\title{
Gut Microbiome Composition is Associated with Age and Memory Performance in Pet Dogs
}

\author{
Eniko Kubinyi ${ }^{1, *,+} \mathbb{C}^{\circ}$, Soufiane Bel Rhali ${ }^{1,2,+}$, Sára Sándor ${ }^{1}{ }^{\circledR}$, Attila Szabó ${ }^{2}$ and \\ Tamás Felföldi ${ }^{2}$ (D) \\ 1 Department of Ethology, ELTE Eötvös Loránd University, 1117 Budapest, Hungary; \\ belghalisoufiane@gmail.com (S.B.R.); sandorsara@gmail.com (S.S.) \\ 2 Department of Microbiology, ELTE Eötvös Loránd University, 1117 Budapest, Hungary; \\ attila.szabo.ttk@gmail.com (A.S.); tamas.felfoldi@gmail.com (T.F.) \\ * Correspondence: eniko.kubinyi@ttk.elte.hu \\ + These authors contributed equally to this work.
}

Received: 25 July 2020; Accepted: 18 August 2020; Published: 24 August 2020

Simple Summary: The intestinal tract affects the brain through metabolites produced by gut-inhabiting bacteria. In this study, we show that the number of errors the dogs commit in a short-term memory test and also their age is linked to the gut microbiome composition. The proportion of Fusobacteria is lower in older animals. Dogs with better memory performance (i.e., fewer mistakes) have relatively fewer Actinobacteria in their fecal samples collected right after the behavior test. This result is in agreement with the high abundance of some Actinobacteria in the gastrointestinal tract of persons living with Alzheimer's disease. Links between memory performance and gut microbiota have been reported on rodents but not on dogs before. The research opens up new venues in canine aging and neurodevelopmental research.

\begin{abstract}
Gut microbiota can crucially influence behavior and neurodevelopment. Dogs show unique similarities to humans in their physiology and may naturally develop dementia-like cognitive decline. We assessed 29 pet dogs' cognitive performance in a memory test and analyzed the bacterial $16 \mathrm{~S}$ rRNA gene from fecal samples collected right after the behavioral tests. The major phyla identified in the dog microbiomes were Bacteroidetes, Firmicutes, and Fusobacteria, each represented by $>20 \%$ of the total bacterial community. Fewer Fusobacteria were found in older dogs and better memory performance was associated with a lower proportion of Actinobacteria. Our preliminary findings support the existence of links between gut microbiota, age, and cognitive performance in pet dogs.
\end{abstract}

Keywords: gut microbiome; dog; cognition; aging

\section{Introduction}

The intestinal tract harbors the most abundant and diverse collection of microbes in the body. Several studies performed in rodents suggest that neurodevelopment is affected by gut microbiota [1-3]. In humans, intestinal microbiome composition has been linked to psychiatric conditions, such as depression, anxiety, and autism, as well as neurodegenerative disorders, including Parkinson's and Alzheimer's disease [4]. The primary path through which the gut microbiome is thought to affect behavior are metabolites produced by gut-inhabiting bacteria. Some of them (such as Lactobacillus and Bifidobacterium) can produce neurotransmitters or other molecules, including $\gamma$-aminobutyric acid (GABA), amino-acid derivatives (e.g., serotonin, melatonin, and histamine), fatty-acid derivatives (e.g., acetylcholine), or catecholamines (e.g., dopamine and norepinephrine $[5,6])$. It has therefore been 
postulated that a regulatory pathway, called the gut-brain axis, exists between the enteric nervous system of the gastrointestinal tract (GIT) and the central nervous system [7].

Dogs have become a valuable model of human complex traits and disorders $[8,9]$. The wide range of expected lifespans, a natural risk to develop dementia, and an environment shared with humans, has also made dogs a promising model organism in aging research (for a review see [10]). Since laboratory dogs represent a limited sample of the natural genetic and environmental variability found in human populations and companion (or pet) dogs, the latter has gained more popularity in aging research recently [11-18]. Their behavior also differs from that of laboratory dogs [19] in ways that make the companion dog a more ecologically valid model of human aging.

The gut microbiome of dogs is more similar to that of humans than that of mice and pigs [20]. Although studies on dogs' microbiota and their connection to disease prevalence and aging are still scarce [21,22], they suggest that nutritional supplements may improve some of the symptoms of age-related pathological cognitive decline in dogs [23].

Next-generation DNA sequencing techniques have enabled the detailed determination of the taxonomic composition and also the potential functions of the microorganisms, gaining a better understanding of microbial-host interactions [24]. We selected this technique for the analysis of the gut microbiome of a group of companion dogs and examined possible links with age and cognitive performance. Based on a study in mice, we predicted that memory performance is linked to Lactobacillus [25] and that age would be associated with less diverse microbiota $[21,26]$ and/or less abundant lactobacilli [24].

\section{Materials and Methods}

\subsection{Ethics Statement}

The behavioral observations conducted in this study complied with national (Hungarian law ('1998. évi XXVIII. Törvény' 3. §/9.-The Animal Protection Act)) and EU legislation, as well as institutional guidelines. The Hungarian "Animal Experiments Scientific and Ethical Committee" approved the experimental procedures under the numbers: PE/EA/2019-5/2017. The owners provided written consent for their dogs' participation. The information included the owners' right to withdraw their consent at any time. The owners could at any point decline to participate with their dog and could request their data not to be used and/or deleted after collection. Non-invasive behavior tests are not considered as an animal experiment and are therefore allowed to be conducted without any special permission from the University Institutional Animal Care and Use Committee (UIACUC). The study was performed in strict accordance with the recommendations in the International Society for Applied Ethology guidelines for the use of animals in research.

\subsection{Subjects}

Companion dogs ( $\mathrm{N}=29,14$ males, age range: 3 to 13-year-old, mean age (SD): 9.7 (2.6) years, mean weight (SD): 23.3 (14.3) kg; 1 Bernese mountain dog, 6 Border collies, 2 Cairn terriers, 1 German wirehaired pointer, 1 Labrador retriever, 12 Mixed breeds, 1 Moscow watchdog, 2 Vizslas, 3 Whippets) living in Hungarian households were included in the study. The dogs participated in a larger study investigating the behavioral signs of aging [27]. These dogs had defecated right after the behavior tests and were thus included here due to the availability of fecal samples. Based on the owners' reports, dry food was the main diet for 8 dogs, cooked food for 1 dog, raw meat for 2, and mixed food (i.e., no "main" food type could be specified) for 18 dogs. Three dogs received (unspecified) vitamins/nutritional supplements daily, 7 often, 6 rarely, 13 never. Three dogs were classified by their owners as "obese", 1 as "thin" and 25 as "normal" weight. In the case of 6 individuals, fecal samples could also be collected after a 3-month interval, since they again participated in the behavior test and defecated. 


\section{3. $16 \mathrm{~S}$ rRNA Gene Amplicon Sequencing}

Fecal samples were collected immediately after the dogs had participated in the behavior tests (see below). The samples were collected after spontaneous defecation and conserved at $-80{ }^{\circ} \mathrm{C}$ within $15 \mathrm{~min}$. The gut microbiome analysis was performed on the samples using amplicon sequencing of the bacterial $16 \mathrm{~S}$ rRNA gene. Total genomic DNA extraction was performed using the QIAamp Power Fecal DNA kit (Qiagen, Venlo, Netherlands) following the instructions given by the manufacturer. DNA sequencing was performed on an Illumina MiSeq platform using MiSeq standard v2 chemistry as a service provided by the Genomics Core Facility RTSF, Michigan State University, East Lansing MI, USA. Methodological details and instructions for the bioinformatic analysis are given in [28]. Briefly, sequences were processed using the Mothur software [29] reads were quality-filtered, chimeras (identified by the program described in [30]), and singletons were removed from the dataset. Sequences were preclustered and operational taxonomic units (OTUs) were defined at a $97 \%$ nucleotide sequence similarity level. Taxonomic assignment applying 1000 iterations and bootstrap with a cutoff at 80 was carried out using the ARB SILVA SSU Ref NR 132 [31] database. Reads of non-bacterial origin were removed from the dataset. Raw amplicon sequence data were submitted to NCBI under BioProject ID PRJNA603883.

\subsection{Assessing the Cognitive Performance: Memory Test}

The detailed procedure of the behavior test is described in [27,32]. In short, five identical, open containers were positioned in equal distance from each other in a semi-circular arrangement, each container being two meters away from the starting position of the dog. A dog witnessed the baiting of one of the containers with a treat and then left the room for $30 \mathrm{~s}$. Then the dog was returned to the starting position and was set free to find the baited container. The task was repeated five times and each container was baited once in a semi-randomized order. All dogs obtained the reward within $30 \mathrm{~s}$ in each trial. The measured variable was "memory test mistakes": the number of investigating an unbaited container during the five trials (since the dogs could visit any number of containers until they found the right location).

\subsection{Statistical Analysis and Ordination}

For the statistical analysis of amplicon sequencing data, the subsampling of reads was performed to the read number of the smallest dataset $(\mathrm{N}=28,489)$. The test-retest reliability of gut microbiota composition was investigated with Wilcoxon signed-rank tests at the phylum-level, which did not detect a change in the microbiota composition. We carried out four regression tree analyses, one for age and one for memory mistakes on both the phylum level and genus level, to examine their relationship with the bacterial phyla, richness estimators (sobs, ACE, Chao-1), and diversity values (inverse Simpson) of the gut microbiota. We chose regression trees because they are ideal for analyzing complex numeric and/or categorical data and detecting non-linear relationships (see description in [33]). We used the chi-square automatic interaction detection (CHAID) method and specified the minimum number of cases as 29 for parent nodes and 9 for child nodes. IBM SPSS v25 and non-metric multidimensional scaling (NMDS) ordination with R (R Core Team, 2017) were used for the analyses.

\section{Results}

\subsection{Gut Microbiome Composition}

A total of 1,857,465 high-quality bacterial $16 \mathrm{~S}$ rRNA gene sequences were obtained from the first fecal samples (51,596 $\pm 14,774$ reads per sample). Good's coverage values were higher than 0.99 in all cases, which indicated that sequencing depth was sufficient to recover all major taxa. The average length of sequences was $452 \mathrm{nt}$, which allowed for genus-level taxon identification. 
The major phyla identified in the dog microbiomes were Bacteroidetes, Firmicutes, and Fusobacteria (represented by $>20 \%$ of the total bacterial community on average, Table 1, Figure 1), and the main genera were Fusobacterium, Bacteroides, Prevotella, Peptoclostridium, and Alloprevotella ( $>5 \%$ on average, Table 1, Figure 2).

Table 1. Microbial community of companion dogs' microbiome at the phylum level and genus level in percentages.

\begin{tabular}{|c|c|c|c|c|}
\hline Phylum & Mean & Standard Deviation & Minimum & Maximum \\
\hline Actinobacteria & 1.9 & 2.7 & 0.0 & 11.7 \\
\hline Bacteroidetes & 33.3 & 14.7 & 5.4 & 55.1 \\
\hline Epsilonbacteraeota & 0.7 & 1.5 & 0.0 & 6.4 \\
\hline Firmicutes & 33.0 & 16.5 & 6.8 & 73.9 \\
\hline Fusobacteria & 24.4 & 10.1 & 0.0 & 41.9 \\
\hline Proteobacteria & 6.5 & 7.5 & 0.1 & 25.4 \\
\hline Other bacteria & 0.2 & 0.2 & 0.0 & 0.7 \\
\hline Genus & Mean & Standard Deviation & Minimum & Maximum \\
\hline Allobaculum & 0.5 & 1.1 & 0.0 & 5.4 \\
\hline Alloprevotella & 5.2 & 5.3 & 0.0 & 16.9 \\
\hline Anaerobiospirillum & 1.3 & 3.4 & 0.0 & 17.5 \\
\hline Bacteroides & 21.1 & 14.1 & 4.1 & 51.6 \\
\hline Blautia & 2.5 & 2.8 & 0.0 & 11.2 \\
\hline Catenibacterium & 0.6 & 1.5 & 0.0 & 7.1 \\
\hline Clostridium & 1.0 & 1.8 & 0.0 & 7.6 \\
\hline Collinsella & 1.6 & 2.5 & 0.0 & 11.3 \\
\hline Dialister & 0.5 & 2.6 & 0.0 & 13.8 \\
\hline Erysipelotrichaceae bacterium & 0.1 & 0.3 & 0.0 & 1.2 \\
\hline Escherichia-Shigella & 3.1 & 6.1 & 0.0 & 24.5 \\
\hline Fusobacterium & 24.2 & 10.0 & 0.0 & 41.6 \\
\hline Helicobacter & 0.6 & 1.6 & 0.0 & 6.4 \\
\hline Holdemanella & 0.8 & 2.7 & 0.0 & 14.5 \\
\hline Lachnospira & 0.5 & 1.5 & 0.0 & 8.0 \\
\hline Lachnospiraceae bacterium & 5 & 4.4 & 0.8 & 18.5 \\
\hline Lactobacillus & 1.3 & 6.6 & 0.0 & 35.5 \\
\hline Megamonas & 4.6 & 6.3 & 0.0 & 29.6 \\
\hline Peptoclostridium & 5.8 & 7.5 & 0.0 & 34.0 \\
\hline Peptostreptococcaceae bacterium & 0.7 & 1.6 & 0.0 & 8.2 \\
\hline Phascolarctobacterium & 1.8 & 3.3 & 0.0 & 16.3 \\
\hline Prevotella & 6.2 & 9.4 & 0.0 & 35.1 \\
\hline Sarcina & 0.8 & 3.8 & 0.0 & 20.5 \\
\hline Streptococcus & 0.6 & 1.1 & 0.0 & 3.9 \\
\hline Sutterella & 1.4 & 1.8 & 0.0 & 9.0 \\
\hline Turicibacter & 1.1 & 2.4 & 0.0 & 9.5 \\
\hline Other bacteria & 7.0 & 4.0 & 0.2 & 15.9 \\
\hline
\end{tabular}




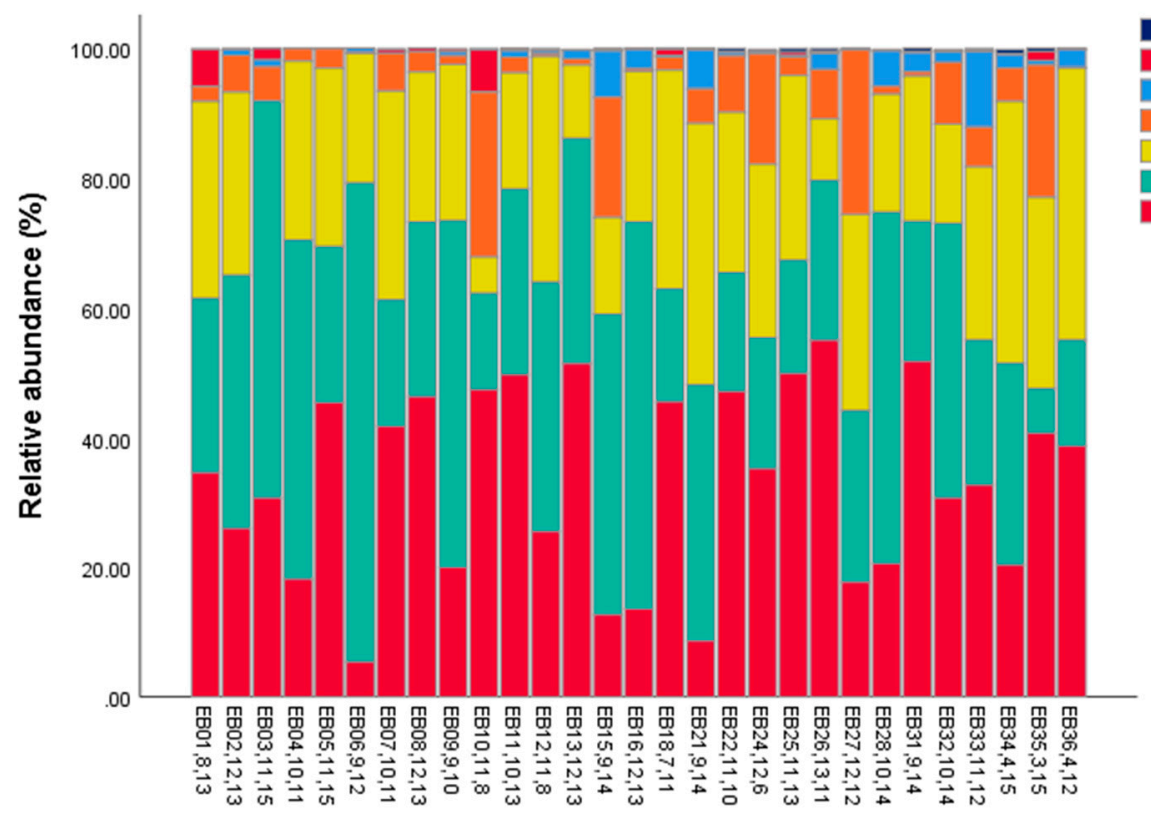

Other bacteria

Epsilonbacteraeota

Actinobacteria

Proteobacteria

$\square$ Fusobacteria

Firmicutes

Bacteroidetes

Dog ID, age (years), number of memory test mistakes

Figure 1. Phylum-level gut microbiota composition in the fecal samples of 29 companion dogs.



Figure 2. Genus-level gut microbiota composition in the fecal samples of 29 companion dogs.

\subsection{Gut Microbiota Composition Associations with Age and Memory Performance}

Higher age was associated with a lower proportion of Fusobacteria $(F=13.349, p=0.010$, Figure 3A). Higher cognitive performance (i.e., fewer errors in the short-term memory-test) was linked to a lower proportion of Actinobacteria $(F=9.203, p=0.042$, Figure 3B). According to NMDS ordination, the general composition of bacterial communities was not directly linked with cognitive performance (Figure S1). No other significant correlations were revealed for other taxa (at the phylum level or genus level) or diversity and richness measures. 
A

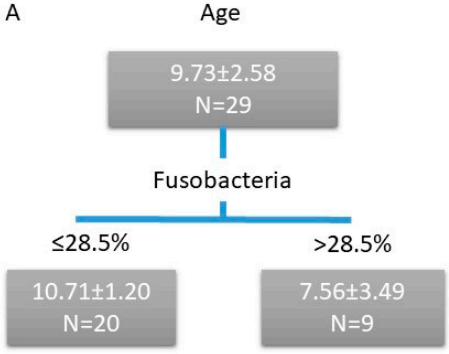

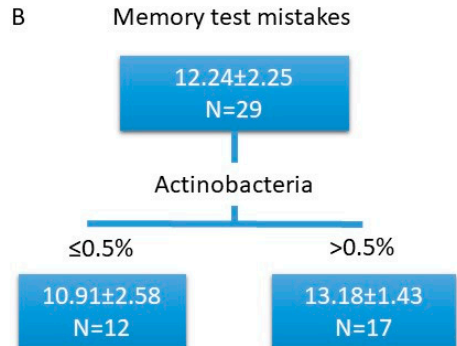

Figure 3. Regression tree model for age (A) and memory test mistakes (B). Scores in the rectangles (subgroups): mean \pm SD.

\section{Discussion}

In this study, we measured pet dogs' microbiome composition and examined its links with age and memory performance. The most abundant phyla were Bacteroidetes and Firmicutes ( $33 \%$ both), next the Fusobacteria (24\%), followed by Proteobacteria (7\%) and Actinobacteria (2\%). These proportions are comparable to the results of [34]. They described the following fecal microbiome composition in six healthy dogs: Bacteroidetes (31-34\%), Firmicutes (14-28\%), Fusobacteria (23-40\%), Proteobacteria $(\sim 7 \%)$, and Actinobacteria (1\%). Other studies identified the same predominant phyla, but the proportions varied greatly within and between the studies (e.g., [35-37]). Differences likely arise due to factors such as breed, age, diet, and living conditions [38]. Based on a sub-sample, the microbiome composition does not seem to have changed notably within a 3-month interval. Other works $[37,39]$ also indicate that a dog's microbiome composition may remain relatively constant for several weeks or months, even when moderate changes in the diet are applied.

Regarding age-related differences, we could not confirm the results of previous studies performed on purebred dogs. Common findings are the decrease in gut microbiome diversity and an abundance of lactobacilli with increased age $[21,24,26]$. In our sample, encompassing several breeds, we instead observed a significant decline in Fusobacteria with age, not described previously in the literature. In contrast to our result, Fusobacteria showed not lower but higher prevalence (the percentage of positive samples) in human centenarians than in elderly and young adults [40]. In agreement with the possibly inverse role of Fusobacteria in the aging of humans and dogs, a higher proportion of Fusobacteria is associated with a healthy microbiota [17,22,41] (and obesity [42]) in dogs, while in humans they are implicated in dysbiosis, e.g., in inflammatory bowel disease [42], colorectal cancer [42], and acute appendicitis [43]. Fusobacteria are more abundant in carnivores than in humans and our data support the assumption of other studies [44-46] that they play a substantially different, possibly beneficial role in the carnivore digestive system. Fusobacteria are also present in a greater relative abundance in the fecal samples of non-aggressive dogs [47] and dogs with access to the outdoors [22,48].

Memory performance was also associated with microbiota composition: dogs with lower performance (i.e., more memory test mistakes) had relatively more Actinobacteria in their fecal samples. This result is in agreement with the high abundance of some Actinobacteria in the GIT of Alzheimer's patients [49].

The limitations of the study include a relatively low number of young dogs, a small sample size for testing behavioral associations, and a high variation in breed and feeding regime. This study was observational using a cross-sectional design and our findings must be further validated. On the other hand, the number of dog microbiome samples was comparable to that of recent studies with 30-45 samples (e.g., [21,36,47]). 


\section{Conclusions}

A link between cognitive performance, age, and gut microbiome composition in companion dogs was hypothesized but not described before. Our research, although preliminary regarding the association between cognition and gut microbiome composition, opens up new venues in canine aging and neurodevelopmental research. Dogs have recently also been proposed as natural models of human autism [50], in which the relevance of microbial dysbiosis has been documented [51]. However, the inverse role of Fusobacteria in human and dog dysbiosis and age highlights the need for more studies to investigate the function these bacteria play in the carnivore digestive system.

Supplementary Materials: The following is available online at http://www.mdpi.com/2076-2615/10/9/1488/s1, Figure S1: Two-dimensional non-metric multidimensional scaling (NMDS) plot of the microbial community composition (on genus-level) in the fecal samples of 29 pet dogs (EBs). The plot is based on the Bray-Curtis distance of the bacterial OTUs (OTUs contributed to $70 \%$ variance between samples by SIMPER analysis are shown in gray). Color coding of samples is according to the number of mistakes in the short-term memory test.

Author Contributions: Conceptualization, E.K. and T.F.; methodology, E.K. and T.F.; formal analysis, E.K., S.B.R., and A.S.; resources, E.K.; data curation, E.K., S.B.R. and S.S.; writing-original draft preparation, E.K., S.B.R., and T.F.; writing-review and editing, all authors; visualization, E.K.; supervision, E.K.; project administration, S.S.; funding acquisition, E.K. All authors have read and agreed to the published version of the manuscript.

Funding: This study has received funding from the European Research Council (ERC) under the European Union's Horizon 2020 research and innovation program (Grant Agreement No. 680040) and Lallemand Animal Nutrition. T. Felföldi was supported by the János Bolyai Research Scholarship of the Hungarian Academy of Sciences (grant no. BO/00837/20/8).

Acknowledgments: We are grateful to Dora Szabo, Anna Egerer, Zsofia Bognar, Andrea Piseddu, and Flora Szantho for the data collection, Patrizia Piotti, Attila Salamon, Borbala Turcsan Cecilia Carreiro, Ivaylo B. Iotchev for commenting on the manuscript.

Conflicts of Interest: The authors declare no conflict of interest. The funders had no role in the design of the study; in the collection, analyses, or interpretation of data; in the writing of the manuscript, or in the decision to publish the results.

\section{References}

1. Clarke, G.; Grenham, S.; Scully, P.; Fitzgerald, P.; Moloney, R.D.; Shanahan, F.; Dinan, T.G.; Cryan, J.F. The microbiome-gut-brain axis during early life regulates the hippocampal serotonergic system in a sex-dependent manner. Mol. Psychiatry 2013, 18, 666-673. [CrossRef] [PubMed]

2. Desbonnet, L.; Clarke, G.; Shanahan, F.; Dinan, T.G.; Cryan, J.F. Microbiota is essential for social development in the mouse. Mol. Psychiatry 2014, 19, 146-148. [CrossRef] [PubMed]

3. Stilling, R.M.; Ryan, F.J.; Hoban, A.E.; Shanahan, F.; Clarke, G.; Claesson, M.J.; Dinan, T.G.; Cryan, J.F. Microbes \& neurodevelopment-Absence of microbiota during early life increases activity-related transcriptional pathways in the amygdala. Brain. Behav. Immun. 2015, 50, 209-220. [CrossRef] [PubMed]

4. Ambrosini, Y.M.; Borcherding, D.; Kanthasamy, A.; Kim, H.J.; Willette, A.A.; Jergens, A.; Allenspach, K.; Mochel, J.P. The Gut-Brain Axis in Neurodegenerative Diseases and Relevance of the Canine Model: A Review. Front. Aging Neurosci. 2019, 11, 130. [CrossRef] [PubMed]

5. Barrett, E.; Ross, R.P.; O’Toole, P.W.; Fitzgerald, G.F.; Stanton, C. $\gamma$-Aminobutyric acid production by culturable bacteria from the human intestine. J. Appl. Microbiol. 2012, 113, 411-417. [CrossRef] [PubMed]

6. Strandwitz, P. Neurotransmitter modulation by the gut microbiota. Brain Res. 2018, 1693, 128-133. [CrossRef]

7. Foster, J.A.; McVey Neufeld, K.-A. Gut-brain axis: How the microbiome influences anxiety and depression. Trends Neurosci. 2013, 36, 305-312. [CrossRef]

8. Topál, J.; Miklósi, Á.; Gácsi, M.; Dóka, A.; Pongrácz, P.; Kubinyi, E.; Virányi, Z.; Csányi, V. The Dog as a Model for Understanding Human Social Behavior. In Advances in the Study of Behavior; Brockmann, H.J., Roper, T.J., Naguib, M., Wynne-Edwards, K.E., Mitani, J.C., Simmons, L.W., Eds.; Academic Press: Burlington, VT, USA, 2009; Volume 39, pp. 71-116. ISBN 9780123744746. 
9. Sutter, N.B.; Ostrander, E.A. Dog star rising: The canine genetic system. Nat. Rev. Genet. 2004, 5, 900-910. [CrossRef]

10. Sándor, S.; Kubinyi, E. Genetic pathways of aging and their relevance in the dog as a natural model of human aging. Front. Genet. 2019, 10, 948. [CrossRef]

11. Kubinyi, E.; Iotchev, I.B. A Preliminary Study toward a Rapid Assessment of Age-Related Behavioral Differences in Family Dogs. Animals 2020, 10, 1222. [CrossRef]

12. Szabó, D.; Miklósi, Á.; Kubinyi, E. Owner reported sensory impairments affect behavioural signs associated with cognitive decline in dogs. Behav. Processes 2018, 157, 354-360. [CrossRef] [PubMed]

13. Jónás, D.; Sándor, S.; Tátrai, K.; Egyed, B.; Kubinyi, E. A Preliminary Study to Investigate the Genetic Background of Longevity Based on Whole-Genome Sequence Data of Two Methuselah Dogs. Front. Genet. 2020, 11, 315. [CrossRef] [PubMed]

14. Chapagain, D.; Range, F.; Huber, L.; Virányi, Z. Cognitive Aging in Dogs. Gerontology 2018, 64, $165-171$. [CrossRef] [PubMed]

15. Urfer, S.R.; Kaeberlein, T.L.; Mailheau, S.; Bergman, P.J.; Creevy, K.E.; Promislow, D.E.L.; Kaeberlein, M. A randomized controlled trial to establish effects of short-term rapamycin treatment in 24 middle-aged companion dogs. GeroScience 2017. [CrossRef]

16. Wallis, L.J.; Szabó, D.; Erdélyi-Belle, B.; Kubinyi, E. Demographic Change Across the Lifespan of Pet Dogs and Their Impact on Health Status. Front. Vet. Sci. 2018, 5, 200. [CrossRef]

17. Mongillo, P.; Araujo, J.A.; Pitteri, E.; Carnier, P.; Adamelli, S.; Regolin, L.; Marinelli, L. Spatial reversal learning is impaired by age in pet dogs. Age (Omaha) 2013, 35, 2273-2282. [CrossRef]

18. Mongillo, P.; Pitteri, E.; Carnier, P.; Gabai, G.; Adamelli, S.; Marinelli, L. Does the attachment system towards owners change in aged dogs? Physiol. Behav. 2013, 120, 64-69. [CrossRef]

19. Turcsán, B.; Tátrai, K.; Petró, E.; Topál, J.; Balogh, L.; Egyed, B.; Kubinyi, E. Comparison of Behavior and Genetic Structure in Populations of Family and Kenneled Beagles. Front. Vet. Sci. 2020, 7, 183. [CrossRef]

20. Coelho, L.P.; Kultima, J.R.; Costea, P.I.; Fournier, C.; Pan, Y.; Czarnecki-Maulden, G.; Hayward, M.R.; Forslund, S.K.; Schmidt, T.S.B.; Descombes, P.; et al. Similarity of the dog and human gut microbiomes in gene content and response to diet. Microbiome 2018, 6, 72. [CrossRef]

21. Mizukami, K.; Uchiyama, J.; Igarashi, H.; Murakami, H.; Osumi, T.; Shima, A.; Ishiahra, G.; Nasukawa, T.; Une, Y.; Sakaguchi, M. Age-related analysis of the gut microbiome in a purebred dog colony. FEMS Microbiol. Lett. 2019, 366. [CrossRef]

22. Pilla, R.; Suchodolski, J.S. The Role of the Canine Gut Microbiome and Metabolome in Health and Gastrointestinal Disease. Front. Vet. Sci. 2020, 6, 498. [CrossRef]

23. Heath, S.E.; Barabas, S.; Craze, P.G. Nutritional supplementation in cases of canine cognitive dysfunction-A clinical trial. Appl. Anim. Behav. Sci. 2007, 105, 284-296. [CrossRef]

24. Masouka, H.; Shimada, K.; Kiyosue-Yasuda, T.; Kiyosue, M.; Oishi, Y.; Kimura, S.; Yamada, A.; Hirayama, K. Transition of the intestinal microbiota of dogs with age. Biosci. Microbiota Food Heal. 2017, 36, 27-31. [CrossRef] [PubMed]

25. Mao, J.H.; Kim, Y.M.; Zhou, Y.X.; Hu, D.; Zhong, C.; Chang, H.; Brislawn, C.; Langley, S.; Wang, Y.; Peisl, B.Y.L.; et al. Genetic and metabolic links between the murine microbiome and memory. Microbiome 2020, 8, 53. [CrossRef] [PubMed]

26. Omatsu, T.; Omura, M.; Katayama, Y.; Kimura, T.; Okumura, M.; Okumura, A.; Murata, Y.; Mizutani, T. Molecular diversity of the faecal microbiota of Toy Poodles in Japan. J. Vet. Med. Sci. 2018, 80, 749-754. [CrossRef]

27. Iotchev, I.B.; Szabó, D.; Kis, A.; Kubinyi, E. Possible association between spindle frequency and reversal learning in aged family dogs. Sci. Rep. 2020. [CrossRef]

28. Benedek, K.; Bálint, J.; Máthé, I.; Mara, G.; Felföldi, T.; Szabó, A.; Fazakas, C.; Albert, C.; Buchkowski, R.W.; Schmitz, O.J.; et al. Linking intraspecific variation in plant chemical defence with arthropod and soil bacterial community structure and N allocation. Plant Soil 2019, 444, 383-397. [CrossRef]

29. Schloss, P.D.; Westcott, S.L.; Ryabin, T.; Hall, J.R.; Hartmann, M.; Hollister, E.B.; Lesniewski, R.A.; Oakley, B.B.; Parks, D.H.; Robinson, C.J.; et al. Introducing mothur: Open-source, platform-independent, community-supported software for describing and comparing microbial communities. Appl. Environ. Microbiol. 2009, 75, 7537-7541. [CrossRef] 
30. Edgar, R.C.; Haas, B.J.; Clemente, J.C.; Quince, C.; Knight, R. UCHIME improves sensitivity and speed of chimera detection. Bioinformatics 2011, 27, 2194-2200. [CrossRef]

31. Quast, C.; Pruesse, E.; Yilmaz, P.; Gerken, J.; Schweer, T.; Yarza, P.; Peplies, J.; Glöckner, F.O. The SILVA ribosomal RNA gene database project: Improved data processing and web-based tools. Nucleic Acids Res. 2012, 41, D590-D596. [CrossRef]

32. Piotti, P.; Szabó, D.; Wallis, L.; Bognár, Z.; Stiegmann, B.S.; Egerer, A.; Marty, P.; Kubinyi, E. The effect of age on visuo-spatial short-term memory in family dogs. Pet Behav. Sci. 2017, 17. [CrossRef]

33. Kubinyi, E.; Turcsán, B.; Miklósi, Á. Dog and owner demographic characteristics and dog personality trait associations. Behav. Processes 2009, 81, 392-401. [CrossRef] [PubMed]

34. Middelbos, I.S.; Vester Boler, B.M.; Qu, A.; White, B.A.; Swanson, K.S.; Fahey, G.C. Phylogenetic Characterization of Fecal Microbial Communities of Dogs Fed Diets with or without Supplemental Dietary Fiber Using 454 Pyrosequencing. PLoS ONE 2010, 5, e9768. [CrossRef] [PubMed]

35. Swanson, K.S.; Dowd, S.E.; Suchodolski, J.S.; Middelbos, I.S.; Vester, B.M.; Barry, K.A.; Nelson, K.E.; Torralba, M.; Henrissat, B.; Coutinho, P.M.; et al. Phylogenetic and gene-centric metagenomics of the canine intestinal microbiome reveals similarities with humans and mice. ISME J. 2011, 5, 639-649. [CrossRef] [PubMed]

36. Schmidt, M.; Unterer, S.; Suchodolski, J.S.; Honneffer, J.B.; Guard, B.C.; Lidbury, J.A.; Steiner, J.M.; Fritz, J.; Kölle, P. The fecal microbiome and metabolome differs between dogs fed Bones and Raw Food (BARF) diets and dogs fed commercial diets. PLoS ONE 2018, 13. [CrossRef] [PubMed]

37. Jarett, J.K.; Carlson, A.; Rossoni Serao, M.; Strickland, J.; Serfilippi, L.; Ganz, H.H. Diets with and without edible cricket support a similar level of diversity in the gut microbiome of dogs. PeerJ 2019, 2019 , e7661. [CrossRef]

38. Kerr, K.R.; Beloshapka, A.N.; Swanson, K.S. 2011 and 2012 early careers acihevement awards: Use of genomic biology to study companion animal intestinal microbiota. J. Anim. Sci. 2013, 91, 2504-2511. [CrossRef]

39. da Fonseca Ferreira, M.; Salavati Schmitz, S.; Schoenebeck, J.J.; Clements, D.N.; Campbell, S.M.; Gaylor, D.E.; Mellanby, R.J.; Gow, A.G.; Salavati, M. Lactulose drives a reversible reduction and qualitative modulation of the faecal microbiota diversity in healthy dogs. Sci. Rep. 2019, 9, 1-11. [CrossRef]

40. Biagi, E.; Nylund, L.; Candela, M.; Ostan, R.; Bucci, L.; Pini, E.; Nikkïla, J.; Monti, D.; Satokari, R.; Franceschi, C.; et al. Through Ageing, and Beyond: Gut Microbiota and Inflammatory Status in Seniors and Centenarians. PLoS ONE 2010, 5, e10667. [CrossRef]

41. Vázquez-Baeza, Y.; Hyde, E.R.; Suchodolski, J.S.; Knight, R. Dog and human inflammatory bowel disease rely on overlapping yet distinct dysbiosis networks. Nat. Microbiol. 2016, 1, 16177. [CrossRef]

42. Gevers, D.; Kugathasan, S.; Denson, L.A.; Vázquez-Baeza, Y.; Van Treuren, W.; Ren, B.; Schwager, E.; Knights, D.; Song, S.J.; Yassour, M.; et al. The treatment-naive microbiome in new-onset Crohn's disease. Cell Host Microbe 2014, 15, 382-392. [CrossRef] [PubMed]

43. Swidsinski, A.; Dörffel, Y.; Loening-Baucke, V.; Theissig, F.; Rückert, J.C.; Ismail, M.; Rau, W.A.; Gaschler, D.; Weizenegger, M.; Kühn, S.; et al. Acute appendicitis is characterised by local invasion with Fusobacterium nucleatum/necrophorum. Gut 2011, 60, 34-40. [CrossRef] [PubMed]

44. Ley, R.E.; Hamady, M.; Lozupone, C.; Turnbaugh, P.J.; Ramey, R.R.; Bircher, J.S.; Schlegel, M.L.; Tucker, T.A.; Schrenzel, M.D.; Knight, R.; et al. Evolution of Mammals and Their Gut Microbes. Science 2008, 320, 1647-1651. [CrossRef] [PubMed]

45. Muegge, B.D.; Kuczynski, J.; Knights, D.; Clemente, J.C.; Gonzalez, A.; Fontana, L.; Henrissat, B.; Knight, R.; Gordon, J.I. Diet Drives Convergence in Gut Microbiome Functions across Mammalian Phylogeny and Within Humans. Science 2011, 332, 970-974. [CrossRef] [PubMed]

46. Nelson, T.M.; Rogers, T.L.; Brown, M.V. The Gut Bacterial Community of Mammals from Marine and Terrestrial Habitats. PLoS ONE 2013, 8, e83655. [CrossRef]

47. Kirchoff, N.S.; Udell, M.A.R.; Sharpton, T.J. The gut microbiome correlates with conspecific aggression in a small population of rescued dogs (Canis familiaris). PeerJ 2019, 7, e6103. [CrossRef]

48. Song, S.J.; Lauber, C.; Costello, E.K.; Lozupone, C.A.; Humphrey, G.; Berg-Lyons, D.; Caporaso, J.G.; Knights, D.; Clemente, J.C.; Nakielny, S.; et al. Cohabiting family members share microbiota with one another and with their dogs. Elife 2013, 2, 1-22. [CrossRef] 
49. Emery, D.C.; Shoemark, D.K.; Batstone, T.E.; Waterfall, C.M.; Coghill, J.A.; Cerajewska, T.L.; Davies, M.; West, N.X.; Allen, S.J. 16S rRNA next generation sequencing analysis shows bacteria in Alzheimer's Post-Mortem Brain. Front. Aging Neurosci. 2017, 9, 1-13. [CrossRef]

50. Topál, J.; Román, V.; Turcsán, B. The dog (Canis familiaris) as a translational model of autism: It is high time we move from promise to reality. Wiley Interdiscip. Rev. Cogn. Sci. 2019, 10, e1495. [CrossRef]

51. Hsiao, E.Y.; McBride, S.W.; Hsien, S.; Sharon, G.; Hyde, E.R.; McCue, T.; Codelli, J.A.; Chow, J.; Reisman, S.E.; Petrosino, J.F.; et al. Microbiota Modulate Behavioral and Physiological Abnormalities Associated with Neurodevelopmental Disorders. Cell 2013, 155, 1451-1463. [CrossRef]

(C) 2020 by the authors. Licensee MDPI, Basel, Switzerland. This article is an open access article distributed under the terms and conditions of the Creative Commons Attribution (CC BY) license (http://creativecommons.org/licenses/by/4.0/). 